\title{
High incidence of hyperventilation syndrome after COVID-19
}

\author{
Jérémie Taverne $^{1}$, Hélène Salvator ${ }^{1,2}$, Cécile Leboulch $^{3}$, Nicolas Barizien $^{3}$, Marie Ballester $^{4}$, \\ Etienne Imhaus ${ }^{4}$, Marie-Laure Chabi-Charvillat ${ }^{5}$, Anne Boulin ${ }^{6}$, Céline Goyard ${ }^{1}$, Alexandre Chabrol ${ }^{1}$, \\ Emilie Catherinot ${ }^{1}$, Claire Givel ${ }^{1}$, Louis-Jean Couderc ${ }^{1,2}$, Colas Tcherakian ${ }^{1}$ \\ ${ }^{1}$ Department of Respiratory Diseases, Foch Hospital, Suresnes, France; ${ }^{2}$ UFR Sciences de la Sante Simone Veil- INSERM UMR 1173, Paris-Saclay \\ University, Montigny-le-Bretonneux, France; ${ }^{3}$ Department of Sports Medicine, Foch Hospital, Suresnes, France; ${ }^{4}$ Department of Emergency Room, \\ Foch Hospital, Suresnes, France; ${ }^{5}$ Department of Radiology, Foch Hospital, Suresnes, France; ${ }^{6}$ Department of Neuroradiology, Foch Hospital, \\ Suresnes, France \\ Correspondence to: Dr. Jérémie Taverne. Department of Respiratory Diseases, Foch Hospital, 40 rue Worth, 92150 Suresnes, France. \\ Email: j.taverne@hopital-foch.com.
}

Submitted Aug 28, 2020. Accepted for publication Apr 29, 2021.

doi: 10.21037/jtd-20-2753

View this article at: http://dx.doi.org/10.21037/jtd-20-2753

The Severe Acute Respiratory Syndrome Coronavirus-type 2 (SARS-Cov-2) infection has caused a global pandemic whose medical consequences in the long term are not yet well known. Although some patients develop pulmonary fibrosis (1), the majority of them recover without sequelae, especially after mild symptoms. The French Pulmonary Society of Respiratory Diseases has proposed guidelines for monitoring patients (2). In case of unexplained persistent respiratory symptoms, it is suggested to look for a cardiac or pulmonary thromboembolic cause or for a hyperventilation syndrome (HVS) (2). HVS is characterized by a wide variety of somatic symptoms induced by inappropriate ventilation and reproduced by voluntary hyperventilation $(3,4)$. HVS is frequently confusing for physicians as the patient may express both cardiorespiratory (dyspnea: thirst for air, difficulty in breathing; sighs; yawning, chest pain; palpitations) and extrarespiratory symptoms (intense asthenia, weakness, confusion, anxiety, dizziness, paresthesia, muscle cramps), that can possibly match to the clinical presentation of COVID (5).

On June 30th, 147 out patients had undergone in our Department a clinical evaluation 3 months after COVID-19 infection with respiratory functional tests and measurement of carbon monoxide diffusing capacity (DLCO), EKG, thoracic computed-tomography (CT)-scan, measurement of blood cells level, D-Dimers and troponin. We dismissed patients with dyspnea and obvious abnormality on one of these tests. Ten out of these 147 patients (7\%) complained of persistent dyspnea unexplained by above investigations.
They presented with a stereotypical symptomatology suggesting a diagnosis of HVS: difficulty in inspiration or chest tightness.

The set of complementary explorations we applied to these 10 patients included the Nijmegen score, a voluntary hyperventilation challenge with $\mathrm{PET}-\mathrm{CO}_{2}$ monitoring, a cardiopulmonary exercise testing (CPET), arterial blood gas analysis, a ventilation/perfusion lung scan, and a cardiac magnetic resonance imagery (MRI). A brain MRI was performed on patients with HVS diagnosis. All patients consented to the use of routine care exam-extracted medical data. This study was approved by the research ethical committee of Foch Hospital (IRB No. IRB00012437).

Among the 10 patients, eight were female, two were male. The COVID-19 infection had been confirmed by reverse transcriptase-polymerase chain reaction test on nasopharyngeal swab for all patients. Two patients had been hospitalized, only one had required oxygen and noninvasive ventilation. Initial thoracic CT-scan had disclosed restricted extension of COVID-related lung infiltrates $(<25 \%)$ and no pulmonary embolism had been diagnosed at the time of COVID-19 diagnosis (all patients underwent a CT-pulmonary angiography at diagnosis). Three patients had been prescribed antibiotics and one had received hydroxychloroquine.

At the time of assessment [median delay from COVID-19 diagnosis, 46 days (IQR 36-60)], all patients complained of dyspnea on both rest and exertion. The major symptoms reported by all patients were difficulties in breathing in or 
chest tightness.

We retained the diagnosis of HVS for $6 / 10$ patients, characterized by a Nijmegen score $>23 / 64$, hypocapnia on blood gas at rest and a positive hyperventilation challenge (induction of two or more symptoms and delayed PET$\mathrm{CO}_{2}$ normalization) (Table 1). All patients with HVS were female, three had a previous diagnosis of mild asthma ( 2 were receiving inhaled corticosteroids) that was controlled with normal functional tests. On CPET, aerobic capacities were conserved. Disharmony in the respiratory pattern during exercise (uncoordinated and anarchical evolution of tidal volume and respiratory rate) was noted for 5/6 patients. Brain MRI of patients with HVS were normal.

Among the four patients without diagnosis of HVS, one was diagnosed with deconditioning, one had a slight increase in alveolar-arterial partial oxygen pressure

Table 1 Clinical and functional characteristics of patients

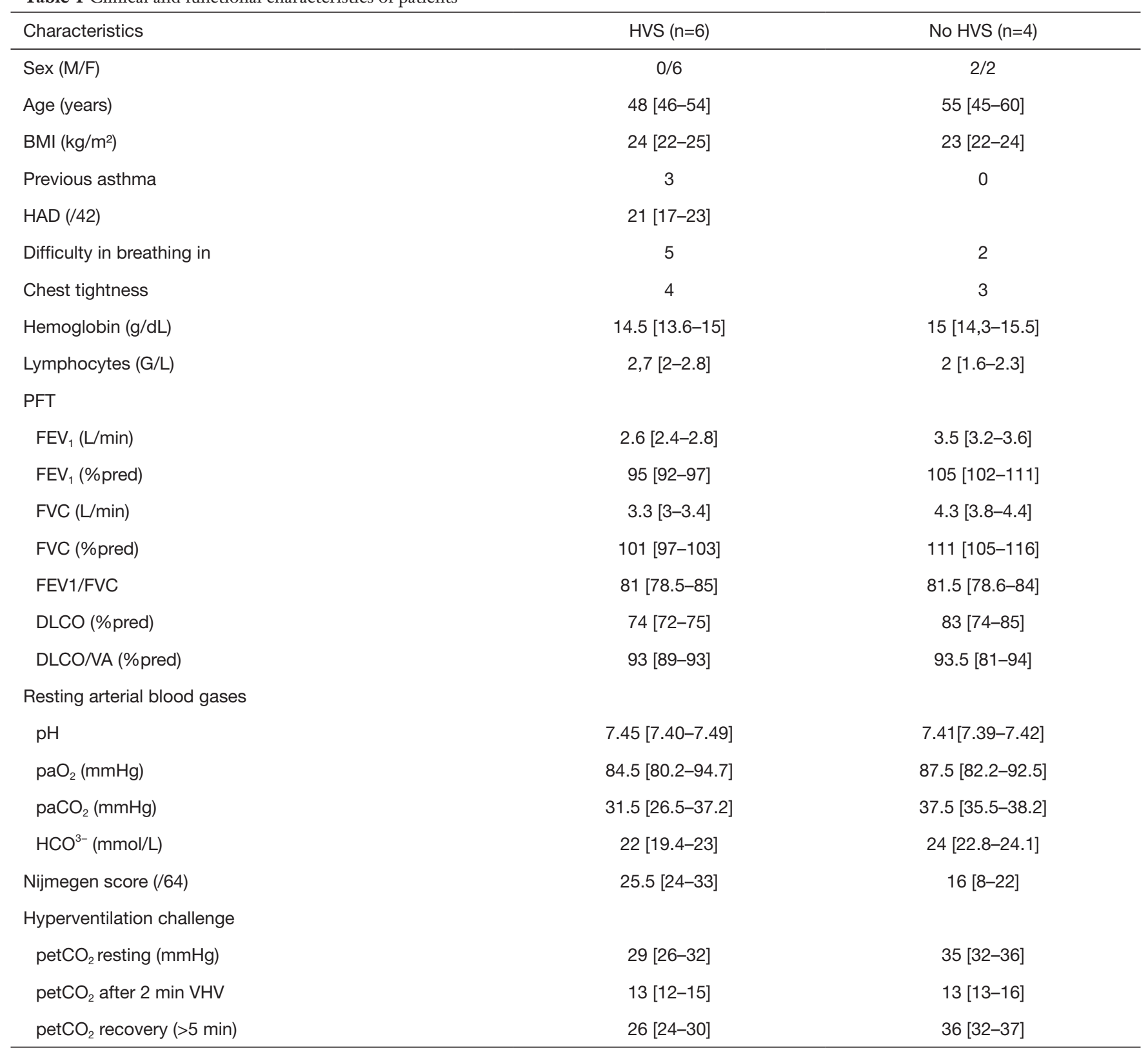

Table 1 (continued) 
Table 1 (continued)

\begin{tabular}{|c|c|c|}
\hline Characteristics & $\operatorname{HVS}(n=6)$ & No HVS $(n=4)$ \\
\hline $\mathrm{VO}_{2}$ peak (mL/kg/min) & 23,8 [22.5-26.5] & 24.2 [23-28] \\
\hline $\mathrm{VO}_{2}$ peak (\%pred) & $108[93-110]$ & 90 [84-100] \\
\hline VE/ $/ \mathrm{N}_{2}$ at VThr & 28.5 [26-32] & 29 [27-30] \\
\hline Vt peak (FVC \%) & 57 [50-63] & 54 [52-55] \\
\hline RR peak (/min) & 39 [36-40] & 36 [34-39] \\
\hline DeltaHR/DeltaVO ${ }_{2}$ peak & 61 [57-69] & $61[48-69]$ \\
\hline $\mathrm{P}(\mathrm{Ai}-\mathrm{a}) \mathrm{O}_{2}$ peak & 26 [24-28] & 21 [15-26] \\
\hline Delta VE/VCO ${ }_{2}$ peak-rest & $-0.1(-0.77$ to -5.9$)$ & $-4.5(-5.5$ to -2$)$ \\
\hline
\end{tabular}

Data are expressed in median [interquartile range]. HAD, Hospitality Anxiety and Depression Scale; HVS, Hyperventilation Syndrome; PFT, pulmonary function testing; $\mathrm{FEV}_{1}$, forced expiratory volume in one second; FVC, forced vital capacity; DLCO, diffusing capacity of the lungs for carbon monoxide, VA, alveolar volume; $\mathrm{VHV}$, voluntary hyperventilation; $\mathrm{CPET}$, cardiopulmonary exercise testing; $\mathrm{VO}_{2}$, oxygen consumption; VE, minute ventilation; VThr, ventilatory threshold; (PAi-a) $\mathrm{O}_{2}$, alveolar-arterial $\mathrm{PO}_{2}$ pressure difference; Vt , tidal volume; RR, respiratory rate; $\mathrm{HR}$, heart rate; $\mathrm{Vd} / \mathrm{Vt}$, dead space-to-tidal volume ratio.

difference related to underlying interstitial lung disease. CPET unmasked mild cardiovascular abnormalities in the last two patients: one with ST segment depression but further normal myocardial perfusion scintigraphy and the second one with and early plateau of max consumption of oxygen $\left(\mathrm{VO}_{2} \mathrm{max}\right)$, leading to the search for defective left ventricle filling on exertion. Cardiac MRIs on rest all showed normal left ventricle ejection fraction and no pericardial nor myocardial abnormalities.

We found a high frequency of post COVID HVS in patients with otherwise unexplained inspiratory dyspnea. As in idiopathic HVS, we observed a female predominance and a high proportion of patients with previous asthma (3).

Although there is no gold standard for the diagnosis of HVS, the combination of Nijmegen score, hyperventilation test and CPET is robust to establish this diagnosis (3).

There were stigmas of cardio-muscular deconditioning for all patients (DeltaHR/DeltaVO $\left.{ }_{2}>50\right)$ that may be due to the lockdown and the reduction of activity secondary to HVS (6).

Ruling out any thrombotic lung disease was essential as COVID-19 is known to cause endothelial damages in various organs (7). This was achieved by normal results of $\mathrm{D}$-dimer values, preserved vascular bed in lung scans, absence of dead space anomalies in CPET results and a normal DLCO. Moreover, absence of both dead space and arterial alveolar gradient anomalies during exercise eliminated pulmonary arterial hypertension.

Other explorations have been useful to eliminate other diagnoses potentially related to COVID-19. HVS is secondary to an inadequate ventilatory control. The brain MRI data confirmed absence of any central abnormality. Myocarditis which is a complication of COVID-19 infection (8) may mimic the symptoms experienced by our patients but was ruled out by normal biological data, EKG and cardiac MRI.

Although the precise pathophysiology of HVS is unknown, the various symptoms seem related to hypocapnia (9). Anxiety is considered to be a trigger of HVS. Since the current pandemic is a source of anxiety, this may explain the resurgence of HVS as a post-traumatic stress (10). The HVS generates also a high degree of anxiety by itself because of its strong impact on the quality of life of patients.

In conclusion, physicians should be aware that HVS is a frequent manifestation of the post-COVID-19 period and leads to chronic dyspnea. In case of highly suggestive clinical symptoms, diagnosis relies on Nijmegen and 
hyperventilation challenge after ruling out pulmonary, vascular and cardiac abnormalities. While the risk factors for developing a severe form of COVID-19 are represented by male sex, age over 65 years, obesity and underlying heart disease, those favoring the appearance of a post-COVID HVS would be the female sex, a mild form of COVID, previous asthma, age under 65 years and the absence of cardiac disorder. Making an HVS diagnosis is of importance because chronic hyperventilation is associated with severe impairment in health-related quality of life while it is accessible to reeducation. The observation of high incidence of HVS after COVID-19 prompted us to create a dedicated respiratory rehabilitation protocol, combining comprehensive physiotherapy and psychological treatment.

\section{Acknowledgments}

Funding: None.

\section{Footnote}

Provenance and Peer Review: This article was a standard submission to the journal. The article has undergone external peer review.

Conflict of Interest: All authors have completed the ICMJE uniform disclosure form (available at http://dx.doi. org/10.21037/jtd-20-2753). Dr. JT reports meeting from Vitalair, outside the submitted work. Dr. HS reports grants from Foch Foundation, grants from Foundation pour la Recherche en Sante respiratoire, grants from Philippe Foundation, personal fees from LVL medical, personal fees from GSK, personal fees from Oxyvie, outside the submitted work. Dr. NB reports meal from Fresenius Kabi France, meal from MERZ Pharma France, personal fees from MEDTRONIC SAS, outside the submitted work. Dr. CG reports meeting from oxyvie, meeting from SOS oxygene, outside the submitted work. Dr. AC reports personal fees and meeting room Boehringer Ingelheim, meeting from LVL medical, meeting from Homeperf, grants and personal fees from Astra ZENEKA, outside the submitted work. Dr. EC reports meeting from LVL medical, meeting from SOS oxygène, meeting from CSC Bearing, personal fees from INsmed, outside the submitted work. Dr. LJC reports personal fees and meeting from Astra Zeneca, personal fees and meeting from Boehringer Ingelheim, meeting from LVL medical, meeting from Elivie, outside the submitted work. Dr. CT reports personal fees and meeting from Laboratoire GlaxoSmithKline, hospitality from LVL Medical, personal fees and hospitality from AstraZeneca, personal fees and hospitality from Boehringer France, hospitality from Novartis Pharma, outside the submitted work. The other authors have no other conflicts of interest to declare.

Ethical Statement: The authors are accountable for all aspects of the work in ensuring that questions related to the accuracy or integrity of any part of the work are appropriately investigated and resolved.

Open Access Statement: This is an Open Access article distributed in accordance with the Creative Commons Attribution-NonCommercial-NoDerivs 4.0 International License (CC BY-NC-ND 4.0), which permits the noncommercial replication and distribution of the article with the strict proviso that no changes or edits are made and the original work is properly cited (including links to both the formal publication through the relevant DOI and the license). See: https://creativecommons.org/licenses/by-nc-nd/4.0/.

\section{References}

1. Cui N, Zou X, Xu L. Preliminary CT findings of coronavirus disease 2019 (COVID-19). Clin Imaging 2020;65:124-32.

2. Andrejak C, Blanc FX, Costes F, et al. Guide for follow-up of patients with SARS-CoV-2 pneumonia. Management proposals developed by the French-language Respiratory Medicine Society. Version of 10 May 2020. Rev Mal Respir 2020;37:505-10.

3. Boulding R, Stacey R, Niven R, et al. Dysfunctional breathing: a review of the literature and proposal for classification. Eur Respir Rev 2016;25:287-94.

4. Tavel ME. Hyperventilation Syndrome: Why Is It Regularly Overlooked? Am J Med 2021;134:13-5.

5. Gavriatopoulou M, Korompoki E, Fotiou D, et al. Organspecific manifestations of COVID-19 infection. Clin Exp Med 2020;20:493-506.

6. Hughson RL, Shoemaker JK. Autonomic responses to exercise: deconditioning/inactivity. Auton Neurosci 2015;188:32-5.

7. Varga Z, Flammer AJ, Steiger P, et al. Endothelial cell infection and endotheliitis in COVID-19. Lancet 2020;395:1417-18

8. De Lorenzo A, Kasal DA, Tura BR, Lamas CC, Rey HC. Acute cardiac injury in patients with COVID-19. Am J 
Cardiovasc Dis 2020;10:28-33.

9. Jack S, Rossiter HB, Pearson MG, et al. Ventilatory responses to inhaled carbon dioxide, hypoxia, and exercise in idiopathic hyperventilation. Am J Respir Crit Care Med
2004;170:118-25.

10. Wang C, Pan R, Wan X, et al. A longitudinal study on the mental health of general population during the COVID-19 epidemic in China. Brain Behav Immun 2020;87:40-8.

Cite this article as: Taverne J, Salvator H, Leboulch C, Barizien N, Ballester M, Imhaus E, Chabi-Charvillat ML, Boulin A, Goyard C, Chabrol A, Catherinot E, Givel C, Couderc LJ, Tcherakian C. High incidence of hyperventilation syndrome after COVID-19. J Thorac Dis 2021;13(6):3918-3922. doi: $10.21037 /$ jtd-20-2753 